Clinical Medicine \& Research

\title{
Review
}

\section{"Heads Up": Concussions in High School Sports}

Fred Theye, PhD, Department of Neuropsychology, Marshfield Clinic, Marshfield, Wisconsin

Karla A. Mueller, PhD, Department of Neuropsychology, Marshfield Clinic, Marshfield, Wisconsin

\begin{abstract}
In the United States, sports-related head injuries occur frequently. The Centers for Disease Control estimates more than 300,000 sports-related concussions occur each year in the United States. There are a number of myths and misunderstandings among health care professionals regarding concussions. In this article, we clarify some reasons for these misunderstandings and provide some of the possible causes for the increased susceptibility of the adolescent athlete, along with evidence-based assessment tools for assisting physicians in making return-to-play decisions. Finally, suggestions for a concussion safety program in the high school setting are also provided.
\end{abstract}

RECEIVED: JANUARY 21, 2004

REPRINT REQUESTS:

Fred Theye, PhD

Department of Neuropsychology

Marshfield Clinic

1000 North Oak Avenue

Marshfield, WI 54449

Telephone: $715-387-5366$

Fax: 715-389-3808

Email: theye.fred@marshfieldclinic.org
REVISED AND ACCEPTED: JUNE 18, 2004

KEYWORDS:

Brain concussion; Head injuries, closed;

Adolescent; Athletic injuries;

Safety management 


\section{INTRODUCTION}

Many physicians serve as the team doctor for their community high schools. The demands of clinical practice may preclude them for staying abreast of the latest evidence-based information regarding management of concussions in their student athletes. Over the past 7 years more than 300 articles have been published on this topic. Prior to this, from 1982 through 1996, only 101 articles had appeared in the literature. ${ }^{1}$ The following new findings have all been demonstrated in recent research:

1. High school athletes are more vulnerable to concussions ${ }^{2-4}$ than older athletes and may take longer to recover. 5,6

2. Failure to properly manage concussion may lead to long-term cumulative consequences. ${ }^{4,7}$

3. Loss of consciousness is not an appropriate marker for the presence or absence of concussion. 8,9

4. High school athletes are 3 times more likely to experience a second concussion if concussed once during a season (GI Iverson, personal communication). ${ }^{10}$

5. More than 5\% of high school athletes are concussed each year while participating in collision sports. ${ }^{3,11-13}$

Nearly 1.5 million head injuries occur in the United States each year. ${ }^{3}$ The Centers for Disease Control estimates more than $20 \%$ of these injuries $(>300,000)$ are sports-related concussions. ${ }^{14}$

There are a number of myths and misunderstandings among health care professionals regarding concussions. This review article will clarify some reasons for these misunderstandings, discuss some of the possible causes for the increased susceptibility of the adolescent athlete, present evidence-based assessment tools to assist the physician in making return-to-play decisions and finally, provide suggestions for a high school concussion safety program.

\section{REASONS FOR INCREASED SUSCEPTIBILITY IN THE ADOLESCENT ATHLETE}

\section{Susceptibility}

Studies have reported that the occurrence of concussions in high school athletes is higher than in older athletes. ${ }^{2-4}$ The unique, increased susceptibility of the high school student athlete can be related to a number of factors which include: the immaturity of the adolescents' central nervous system, the lack of recognition that a concussion had occurred, and the reliance upon subjectivity associated with self-reporting of symptoms.

\section{Nervous system immaturity}

A variety of theories have been offered to explain the finding that the younger brain is more vulnerable to the disruption of autoregulatory functions. These include decreased myelination, a greater head-to-body ratio, and thinner cranial bones, all of which provide less protection to the developing nervous system. In addition, the roles of differences in fitness levels and equipment have been raised as possible explanations for this increased rate of occurrence. ${ }^{3}$ Until all these possibilities are given more scrutiny through further research, those involved with the student athletes will need to develop a concussion safety program that reflects current understandings of management and prevention.

\section{Recognition}

Another primary factor contributing to the increased susceptibility of the high school athlete relates to the frequent lack of recognition that a concussion has even occurred. How to recognize that a concussion had occurred and then assessing its severity "continues to be a difficult problem in the field." 15 These difficulties result, in part, from the inconsistent use of terms and guidelines, and are made even more problematic by the lack of objective, quantifiable measures of the ensuing behaviors. For example, coaches and the popular press use of phrases such as "he had his bell rung" or "he suffered a ding" in describing a blow to the head can lead the athletes and their families to assume that a concussion is just part of the game and that there is no need for concern.

Failure to recognize that a concussion has occurred increases the susceptibility of the student athlete in three ways:

1. A rare but fatal event, second impact syndrome, can occur in which there is massive brain swelling. Typically, this can occur when the student athlete receives a second blow to the head while still experiencing symptoms from the initial concussion. ${ }^{16}$

2. A less serious, but nevertheless debilitating, sequelae is the development of a post-concussion syndrome in which headaches, dizziness, irritability, and eventually depression continue to persist for more than 6 weeks. Approximately $10 \%$ of athletes take more than 7 days to recover from the effects of a concussion. ${ }^{17}$ The activities of daily living for the student athlete become disrupted secondary to their symptoms. Both academic performance and social interactions are impacted, primarily because no explanation for these symptoms has been offered to the athlete, family, or teachers. If an understanding is gained of the changes observed in the athlete being secondary to biological mechanisms, support and accommodations are more likely to be offered. ${ }^{18}$

3. There is clear evidence that effects of concussions are cumulative. ${ }^{19}$ It is, therefore, important to know the concussion history of the athlete when formulating a return to play decision.

\section{Self-Report}

Traditionally, the physician or school relies on the students' self-report of their symptoms to monitor progress and to make decisions about when the athlete can return to play. Reliance on self-report is frankly problematic for two reasons: lack of reliability/validity of those reports, and the athletes' lack of knowledge as to what constitutes a concussion and what its potential implications might be. 
Athletes may be reluctant to report symptoms due to fear they will be removed from the playing field. However, allowing an athlete to return to play based solely on subjective reports of symptoms (or lack of), however, can increase susceptibility for additional injuries. ${ }^{20-24}$

McCrea and colleagues ${ }^{25}$ found that $<50 \%$ of more than 1,500 athletes studied reported their symptoms of concussion to either the certified athletic trainer, coach, or parent suggesting that, in high school football players, concussion may be more common than has previously be reported. The most common reason given for this failure was that the athlete did not think the injury was serious enough to warrant attention. An improved awareness of signs of concussion in the student athlete population is necessary to reduce the potential risks of unreported injury (table 1).

Table 1. Symptoms of concussion*

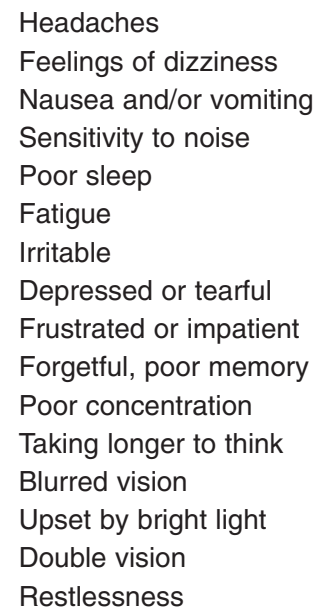

*Players rate severity on scale of 0 (not present) to 6 (severe) on ImPACT test.

Hinton-Bayre and Geffen, ${ }^{26}$ illustrating the reporting bias that exists among athletes, studied 175 Rugby players. They reported on 6 athletes who had a grade I (mild) concussion per the American Academy of Neurology guidelines. Three reported no symptoms 15 minutes after impact, but on neurocognitive measures, performance remained impaired at 10 days post-concussion. ${ }^{26}$ This finding demonstrates the need for a more objective on-field mental status exam that could be used to quantify and judge the veracity of the athlete's self-report.

Self-report questionnaires were given to 529 Canadian soccer and football players before the season. Questions asked whether the athlete had experienced any of the symptoms of concussion during the past year. Over $60 \%$ of the athletes endorsed having some of the symptoms, but only $23 \%$ of the football players and $20 \%$ of soccer players actually realized that he or she had suffered a concussion. ${ }^{27}$ This illustrates the need to provide student athletes information regarding typical post-concussive symptoms and the potential implications of concussion. ${ }^{28}$

\section{Cumulative effects}

It is a common assumption in sports medicine that a history of concussions can predict a lower threshold for a subsequent concussive injury. Additionally, it is thought multiple concussions relate to worse outcomes. Collins and colleagues $^{29}$ studied high school athletes, 60 of whom had no history of concussions and compared them to 38 athletes whose history demonstrated they had suffered at least three concussions. Those athletes who had a previous history of a concussion were 9 times more likely to demonstrate loss of consciousness (LOC) and greater anterograde and retrograde amnesias following a concussion than those without such a history. A second study reported that athletes with a prior history of concussion were 7 times more likely to show drops in memory performance compared to matched cohorts. ${ }^{30}$

Another study demonstrated this cumulative effect at the collegiate level. More than 2,900 football players were followed for 3 years of their football careers. ${ }^{19}$ The study concluded that not only does one concussion increase the risk for a subsequent concussion, but also that a previous history of concussion may lead to slower recovery of functions.

\section{DEFINING CONCUSSIONS}

The Latin origin of the word concussion (concutere) means violent agitation or shaking of the brain. ${ }^{31}$ Historically, concussions were defined on the basis of a LOC. However, LOC has been shown to be a poor indicator of whether or not a concussion had occurred. ${ }^{21}$ Research has moved the understanding of concussion toward a more evidence-based and behaviorally sensitive definition. A universally accepted definition, however, was not developed until 1996 when the Committee of Head Injury Nomenclature, a Congress of Neurological Surgeons in America, reached a consensus on the following definition: a concussion is "... a clinical syndrome characterized by immediate and transient post-traumatic impairment of neural functions, such as alteration of consciousness, disturbance of vision or equilibrium due to brain stem involvement." 32 In other words, multiple nervous system functions are involved following a concussion and being able to objectively assess all of them should be central to any concussion management program.

Multiple studies have shown LOC is not predictive of the symptoms and deficits following a concussion.9,33 Instead, these studies have demonstrated that the presence of amnesia appears to be a more sensitive predictor of symptoms and deficits. LOC occurs when the extracellular potassium concentration increases beyond the upper normal limits (4 to $5 \mathrm{mmol} / \mathrm{l}$ ) to levels of 20 to $50 \mathrm{mmol} / \mathrm{l}$, inhibiting action potential and leading to LOC. ${ }^{31}$ Loss of consciousness, when it occurs, simply represents the most severe level of disturbance.

Current findings suggest that the acceleration, deceleration and rotational forces occurring from a blow to the head 
disrupt the autoregulatory function that balances cellular glucose demands with cerebral blood flow. Concussive symptoms are then postulated to result from a metabolic cascade that involves accelerated glycolysis and increased lactate production that ensues from a blow to the head. ${ }^{34}$ This cascade proposes that disturbances in neurological functioning result from the state of relative ischemia with regard to metabolic demand of the tissue. 35

The disruption of this autoregulatory function is more consistent with the universal definition in that the symptom complex typically seen in concussed athletes includes subtle neurocognitive deficits, postural problems, and somatic complaints (table 1). It becomes incumbent upon the clinician, therefore, to develop methods and measurements that will accurately assess all functions across the spectrum of this injury.

\section{ASSESSMENT ISSUES}

Traditional laboratory (electroencephalogram and brain stem auditory evoked response) and neuroimaging procedures (magnetic resonance imaging and computed tomography) are not helpful in addressing the return-to-play questions because these techniques lack sensitivity in measuring the subtle deficits that affect multiple neurocognitive domains resulting from a concussion. ${ }^{36,37}$

Attempts to grade concussions from mild to severe or Grade I to III have, like the definitional issues discussed previously, made clarity difficult for this field. There are currently more than 17 different published grading systems. The differences between the observations made using these systems make meaningful comparisons between studies impossible and add heterogeneity to the literature. Each of these systems places different levels of weight upon variables such as length of amnesia, intervals of confusion, or length of LOC. Most then link return-to-play decisions to a cumulative score derived from the variables assessed. It can be seen that the definition of confusion, from clinician to clinician, introduces significant variability into the process of judging the severity level of the concussion.

These on-the-sideline systems of grading mental status need to be uniformly administered by a certified athletic trainer with use of standardized questions and techniques. The need certainly exists to estimate the degree of transient disturbance, but these degrees need to be quantifiable and replicable from sideline to sideline and examiner to examiner. The day following a concussion other more sensitive measures can assess neurocognitive dimensions, such as speed of information processing, reaction time, and memory. These measures might also be utilized to assess the degree of disturbance. Although they have been developed with attention to rigorous psychometric principles, ${ }^{38-40}$ these measures are not practical for sideline administration since they require a computer and 20 minutes to administer.
Lovell and colleagues ${ }^{2}$ have reported on 43 high school athletes who suffered Grade I concussions or "dings." These athletes demonstrated some abnormality on mental status exam which cleared 15 minutes later. The athletes were not returned to play even though guidelines would suggest that could be done. Three days later these mildly concussed athletes demonstrated a decrease in memory and an increase in self-report of symptoms when compared to their baseline measurements. The authors concluded, "a reconsideration of current concussion grading systems appears to be warranted."'2

\section{OBJECTIVE TESTING}

Due to the concerns about subjectivity and lack of reliability of the self-report measures, current research has focused on developing a more measurable method for making return-to-play decisions. Over the past 5 years, it has been demonstrated there was a need for pre-season baseline data, a brief on-the-field assessment of mental status, and measures that are sensitive to brain stem functions.

To maximize clinical utility, pre-season baseline testing with neuropsychologic assessment needs to be conducted. Comparing post-concussion testing with a normal population is not appropriate, since some athletes may not fit in the normal range before the concussion for a variety of reasons. Therefore, measuring the athlete against his/her own normal score is the only method by which you can ensure a true return to baseline. ${ }^{41}$

Computerized neuropsychological platforms allow for efficient collection of baseline data and subsequent post-concussion data comparison. These platforms have been developed to specifically probe relevant neurocognitive domains sensitive to transient disturbances in brain functioning. Use of these platforms is becoming more commonplace in managing concussion in high school athletes. Recent studies have suggested neuropsychological testing provides the most promising way to objectively assess concussions. ${ }^{42-44}$

There are currently three computerized platforms all measuring the domains of memory, learning, reaction time, and speed at which information is processed. They take about 20 minutes to administer, have little practice effect and thus can be repeated over the course of several days, and are sensitive to differences of $1 / 100$ th of a second. One of these tests can be administered to multiple athletes simultaneously in a school computer lab (ImPACT), while the other two are web-based programs (CogSport, Headminder). ${ }^{45,46}$ While these tests are very sensitive to neurocognitive functioning, they are all designed to augment, not supplant, clinical decisions.

An on-the-field reliable, quantifiable, and brief test of mental status is available. The Sideline Assessment of Concussion (SAC) has been carefully researched and is similar to the Palm Cards used by many licensed athletic 
trainers and coaches, except that it was developed following established psychometric principles. ${ }^{47-49}$ This instrument has several forms, takes less than 5 minutes to administer, and is inexpensive. It can be easily learned and carried by a licensed athletic trainer or a coach.

While not a direct assessment of cognitive functioning, postural stability has also been shown to be very sensitive to concussions. This makes theoretical sense given that the universal definition noted previously includes brain stem functioning. A measure of postural stability can add yet a third dimension in post-concussion assessment serving to further increase objectivity. While early data on this function was collected on sophisticated equipment in a laboratory, ${ }^{50,51}$ a more practical assessment has been developed and could easily and inexpensively be added to a concussion safety program. The BESS (Balance Error Scoring System) can be conducted on the sideline with the only equipment needed being a piece of foam. Studies in this domain report that problems with balance typically resolve in 3 to 5 days while neurocognitive recovery is still in flux. ${ }^{17}$ Thus, a combination of methodologies that can measure both cortical and brain stem functions may prove the most comprehensive and reliable method by which to assess severity as well as effects of a concussion.

\section{RETURN-TO-PLAY DECISIONS}

In 1988, Cantu noted "decisions on when to allow a football player to return to a game or participate in future contests are arbitrary and based primarily on the experience of the team physician." 52 Despite an additional 15 years of research, the process through which this decision is reached has changed little in most high school athletic programs. Unfortunately, return-to-play decisions are based on experience, not evidence.

Field and colleagues 6 have demonstrated that high school athletes even 7 days following concussion perform worse than age-matched controls on measures of neurocognitve functioning. To further illustrate the increased susceptibility of the younger student athlete, a study at the collegiate level reported, despite more severe in-season concussions, the older athletes performed comparably to age-matched controls at only 3 days following a concussion. ${ }^{6}$

Recovery curves are also dependent upon which function is assessed. In a 3-year study of collegiate athletes, ${ }^{17}$ balance deficits dissipated within 3-5 days, cognitive functioning returned to baseline within 5-7 days, with other somatic symptoms resolved by day 7 . Whether or not this recovery curve will hold true for large numbers of high school athletes awaits further study (figure 1).

Evidence also has been reported that symptoms of concussions resolve more slowly in the adolescent athlete as compared to collegiate athletes. ${ }^{6}$ Specifically, the high school players showed significant memory impairment at day 7 , while the college athletes showed similar deficits only within the 24 hours post injury. These results suggest the current guidelines used to decide when to allow an athlete to return-to-play may not be appropriate for all age groups. ${ }^{6}$

The decision to allow an athlete back into the game should be multifactorial and must include a host of other factors such as a previous history of concussions, time since the last concussion, neurocognitive test recovery compared to baseline, as well as whether the athlete is exhibiting any symptoms at rest or with exertion.

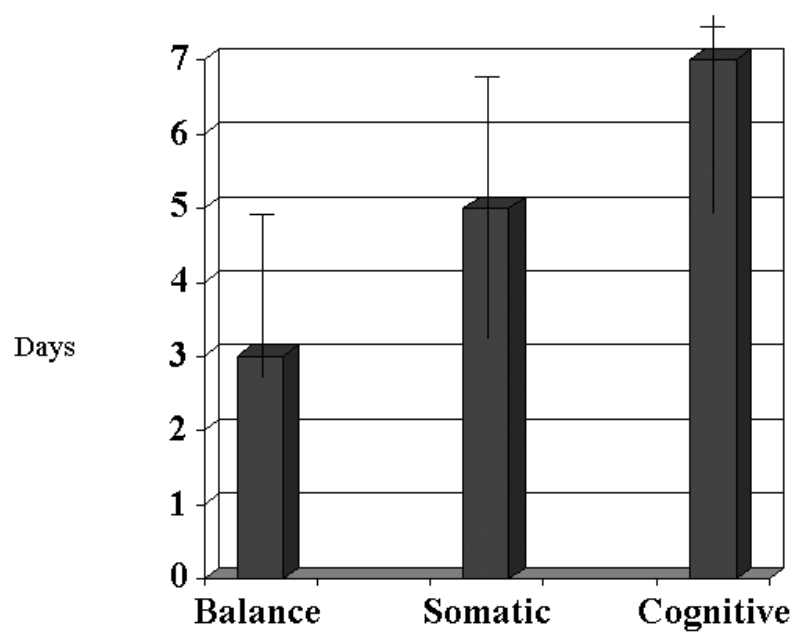

Figure 1. Typical recovery curves for various parameters of adolescent concussions.

\section{CONCLUSIONS}

For the team physicians, when to return a concussed athlete to participation remains a controversial subject despite 17 different sets of guidelines. Every concussion is a unique event and needs to be handled as such "...there is no one formula that can handle an injury this complex and multifaceted issue...."53 The knowledge of the various definitions and management strategies, as well as "the utility of neuropsychological testing, is essential for those involved in decision-making with athletes with mild traumatic brain injuries." 31

A more systematic approach to this disorder needs to be considered to ensure that these vulnerable student athletes can participate safely in school sports. The seminal feature of a concussion safety program is the addition of objective pre-season baselines of subtle neurocognitive functioning. The following are suggested as a guideline for the development of a high school concussion safety program:

1. Recognize that a concussion is a transient disturbance of neurocognitive functioning that may or may not involve a LOC.

2. Acknowledge that younger athletes participating in collision sports are more vulnerable to concussions than older athletes.

3. Recruit the athletic trainer, athletic director, and coaching staff of all collision sports to assist in developing and participating in such programs. 
4. Instruct the student athletes and their families in the symptoms of concussions and their implications.

5. Add objective assessments (neurocognitive testing, standardized sideline mental status evaluation, and postural stability testing) to qualitative information.

6. Consider the athlete's concussion history.

7. Develop a mechanism for informing teachers of the student athlete regarding accommodations necessary following a concussion.

8. Ensure the safety of the student athlete through the nexus of objective measures reflective of transitory disturbances of brain functioning with clinical observation.

\section{ACKNOWLEDGMENTS}

The authors thank Marshfield Clinic Research Foundation for its support through the assistance of Linda Weis, Jennifer Hayes, and Alice Stargardt in the preparation of this manuscript and Pam Mundt for data collection.

\section{REFERENCES}

1. Goodman D, Gaetz M. Return-to-play guidelines after concussion: the message is getting through. Clin J Sport Med 2002; 12:265.

2. Lovell MR, Collins MW, Iverson GL, Johnston KM, Bradley JP. Grade 1 or "ding" concussions in high school athletes. Am J Sports Med 2004;32:47-54

3. McKeever CK, Schatz P. Current issues in the identification, assessment, and management of concussions in sports-related injuries. Appl Neuropsychol 2003;10:4-11.

4. Webbe FM, Barth JT. Short-term and long-term outcome of athletic closed head injuries. Clin Sports Med 2003;22:577-592.

5. Lovell MR, Echemendia RJ, Barth JT, Collins MW. Traumatic brain injury in sports. The Netherlands: Swets \& Zeitlinger; 2004.

6. Field M, Collins MW, Lovell MR, Maroon J. Does age play a role in recovery from sports-related concussion? A comparison of high school and collegiate athletes. J Pediatr 2003; $142: 546-553$.

7. Lovell MR, Collins MW. New developments in the evaluation of sports related concussions. Curr Sports Med Rep 2002;1:287-292.

8. Iverson GL, Lovell MR, Smith SS. Does brief loss of consciousness affect cognitive functioning after mild head injury? Arch Clin Neuropsychol 2000;15:643-648.

9. Collins MW, Iverson GL, Lovell MR, McKeag DB, Norwig J, Maroon J. On-field predictors of neuropsychological and symptom deficit following sports-related concussion. Clin J Sport Med 2003;13:222-229.

10. Zemper ED. Two-year prospective study of relative risk of a second cerebral concussion. Am J Phys Med Rehabil 2003;82:653-659.

11. Powell JW, Barber-Foss K. Traumatic brain injury in high school athletes. JAMA 1999;282:958-963.

12. Ruchinskas RA, Francis JP, Barth JT. Mild head injuries in sports. Appl Neuropsychol 1997;4:43-49.

13. LeBlanc KE. Concussion in sport: diagnosis, management, return to competition. Compr Ther 1999;25:39-44.

14. Sports-related recurrent brain injuries: United States. MMWR Morb Mortal Wkly Rep 1997;46:224-227.

15. Oliaro S, Anderson S, Hooker D. Management of cerebral concussion in sports: the athletic trainer's perspective. J Athl Train 2001;36:257-262.

16. Cantu RC. Head injuries in sport. Br J Sports Med 1996;30:289-296.
17. McCrea M, Guskiewicz KM, Marshall SW, Barr W, Randolph C, Cantu RC, Onate JA, Yang J, Kelly JP. Acute effects and recovery time following concussion in collegiate football players: the NCAA Concussion Study. JAMA 2003;290:2556-2563.

18. Putukian M, Echemendia RJ. Psychological aspects of serious head injury in the competitive athlete. Clin Sports Med 2003;22:617-630.

19. Guskiewicz KM, McCrea M, Marshall SW, Cantu RC, Randolph C, Barr W, Onate JA, Kelly JP. Cumulative effects associated with recurrent concussion in collegiate football players: the NCAA Concussion Study. JAMA 2003;290:2549-2555.

20. Kelly JP, Nichols JS, Filley CM, Lillehei KO, Rubinstein D, Kleinschmidt-DeMasters BK. Concussion in sports. Guidelines for the prevention of catastrophic outcome. JAMA 1991;266:2867-2869.

21. Kelly JP. Loss of consciousness: pathophysiology and implications in grading and safe return to play. J Athl Train 2001;36:249-252.

22. Powell JW. Cerebral concussion: causes, effects, and risks in sports. J Athl Train 2001;36:307-311.

23. Cantu RC. Posttraumatic retrograde and anterograde amnesia: pathophysiology and implications in grading and safe return to play. J Athl Train 2001;36:244-248.

24. Warden DL, Bleiberg J, Cameron KL, Ecklund J, Walter J, Sparling MB, Reeves D, Reynolds KY, Arciero R. Persistent prolongation of simple reaction time in sports concussion. Neurology 2001;57:524-526.

25. McCrea M, Hammeke T, Olsen G, Leo P, Guskiewicz K. Unreported concussion in high school football players: implications for prevention. Clin J Sport Med 2004;14:13-17.

26. Hinton-Bayre AD, Geffen G. Severity of sports-related concussion and neuropsychological test performance. Neurology 2002;59:1068-1070.

27. Delaney JS, Lacroix VJ, Leclerc S, Johnston KM. Concussions among university football and soccer players. Clin J Sport Med 2002;12:331-338.

28. Logan SM, Bell GW, Leonard JC. Acute subdural hematoma in a high school football player after 2 unreported episodes of head trauma: a case report. J Athl Train 2001;36:433-436.

29. Collins MW, Lovell MR, Iverson GL, Cantu RC, Maroon JC, Field M. Cumulative effects of concussion in high school athletes. Neurosurgery 2002;51:1175-1179.

30. Iverson GL, Gaetz M, Lovell MR, Collins MW. Cumulative effects of concussion in amateur athletes. Brain Injury 2004; 18:433-443.

31. Maroon JC, Lovell MR, Norwig J, Podell K, Powell JW, Hartl R. Cerebral concussion in athletes: evaluation and neuropsychological testing. Neurosurgery 2000;47:659-669.

32. Congress of Neurological Surgeons: Proceedings of the Congress of Neurological Surgeons: Report of the Ad Hoc Committee to Study Head Injury Nomenclature. Clin Neurosurg 1996;16:386-394.

33. Lovell MR, Iverson GL, Collins MW, McKeag D, Maroon JC. Does loss of consciousness predict neuropsychological decrements after concussion? Clin J Sport Med 1999;9:193198.

34. Giza CC, Hovda DA. The neurometabolic cascade of concussion. J Athl Train 2001;36:228-235.

35. Yoshino A, Hovda DA, Kawamata T, Katayama Y, Becker DP. Dynamic changes in local cerebral glucose utilization following cerebral conclusion in rats: evidence of a hyperand subsequent hypometabolic state. Brain Res 1991;561:106-119.

36. Eisenberg HM, Levin HS. Computed tomography and magnetic resonance imaging in mild to moderate head injury. In: Levin HS, Eisenberg HM, Benton AL, eds. Mild head injury. New York, NY: Oxford University Press; 1989. 
37. Bigler ED, Snyder JL. Neuropsychological outcome and quantitative neuroimaging in mild head injury. Arch Clin Neuropsychol 1995;10:159-174.

38. Gerberich SG, Priest JD, Boen JR, Straub CP, Maxwell RE. Concussion incidences and severity in secondary school varsity football players. Am J Public Health 1983;73:13701375.

39. Echemendia RJ, Putukian M, Mackin RS, Julian L, Shoss N. Neuropsychological test performance prior to and following sports-related mild traumatic brain injury. Clin J Sport Med 2001;11:23-31.

40. Echemendia RJ, Julian LJ. Mild traumatic brain injury in sports: neuropsychology's contribution to a developing field. Neuropsychol Rev 2001;11:69-88.

41. Grindel SH, Lovell MR, Collins MW. The assessment of sport-related concussion: the evidence behind neuropsychological testing and management. Clin J Sport Med 2001;11:134-143.

42. Patel DR, Greydanus DE. Neurologic considerations for adolescent athletes. Adolesc Med 2002;13:569-578.

43. Collie A, Darby D, Maruff P. Computerised cognitive assessment of athletes with sports related head injury. Br J Sports Med 2001;35:297-302.

44. Schatz P, Browndyke J. Applications of computer-based neuropsychological assessment. J Head Trauma Rehabil 2002; 17:395-410.

45. Erlanger DM, Kaushik T, Broshek D, Freeman J, Feldman D, Festa J. Development and validation of a web-based screening tool for monitoring cognitive status. J Head Trauma Rehabil 2002;17:458-476.

46. Collie A, Maruff P, Makdissi M, McCrory P, McStephen M, Darby D. CogSport: reliability and correlation with conventional cognitive tests used in postconcussion medical evaluations. Clin J Sport Med 2003;13:28-32.

47. McCrea M, Kelly JP, Randolph C, Cisler R, Berger L. Immediate neurocognitive effects of concussion. Neurosurgery 2002;50:1032-1040.

48. McCrea M. Standardized mental status assessment of sports concussion. Clin J Sport Med 2001;11:176-181.

49. McCrea M, Kelly JP, Randolph C, Kluge J, Bartolic E, Finn G, Baxter B. Standardized assessment of concussion (SAC): on-site mental status evaluation of the athlete. J Head Trauma Rehabil 1998;13:27-35.

50. Guskiewicz KM, Riemann BL, Perrin DH, Nashner LM. Alternative approaches to the assessment of mild head injury in athletes. Med Sci Sports Exerc 1997;29(7 Suppl):S213S221.

51. Peterson CL, Ferrara MS, Mrazik M, Piland S, Elliott R. Evaluation of neuropsychological domain scores and postural stability following cerebral concussion in sports. Clin J Sport Med 2003;13:230-237.

52. Cantu RC. Head and spine injuries in the young athlete. Clin Sports Med 1988;7:459-472.

53. Collins MW, Hawn KL. The clinical management of sports concussion. Curr Sports Med Rep 2002;1:12-22. 